\title{
The role of tocopherol cyclase in salt stress tolerance of rice (Oryza sativa)
}

\author{
OUYANG ShouQiang ${ }^{1,2}$, HE SiJie $^{1}$, LIU Peng $^{1,2}$, ZHANG WanKe $^{1}$, \\ ZHANG JinSong ${ }^{1 *}$ \& CHEN Shou Yi ${ }^{1 *}$ \\ ${ }^{1}$ State Key Laboratory of Plant Genomics and National Centre for Plant Gene Research (Beijing), Institute of Genetics and \\ Developmental Biology, Chinese Academy of Sciences, Beijing 100101, China; \\ ${ }^{2}$ Graduate School of the Chinese Academy of Sciences, Beijing, 100049, China
}

Received February 20, 2010; accepted June 28, 2010

\begin{abstract}
Tocopherols synthesized exclusively by photosynthetic organisms are major antioxidants in biomembranes. In plants, tocopherol cyclase (TC/VTE1) catalyzes the conversion of 2,3-dimethyl-5-phytyl-1,4-benzoquinone (DMPBQ) to $\gamma$-tocopherol. In the present study, OSVTE1, which encodes a rice tocopherol cyclase ortholog, was cloned and characterized. OsVTE1 was induced significantly by abiotic stresses such as high salt, $\mathrm{H}_{2} \mathrm{O}_{2}$, drought, cold and by the plant hormones ABA and salicylic acid. The tissue-specific expression pattern and OsVTE1-promoter GUS activity assay showed that OsVTE1 was mainly expressed in the leaf, and also could be detected in the root, stem and panicle. Compared with control plants, transgenic plants with $O s$ VTE1 RNA interference (OSVTE1-RNAi) were more sensitive to salt stress whereas, in contrast, transgenic plants overexpressing OsVTE1 (OsVTE1-OX) showed higher tolerance to salt stress. The DAB in vivo staining showed that OsVTE1-OX plants accumulated less $\mathrm{H}_{2} \mathrm{O}_{2}$ than did control plants.
\end{abstract}

rice, tocopherol, tocopherol cyclase (TC/VTE1), transgenic rice, abiotic stress tolerance

Citation: $\quad$ Ouyang S Q, He S J, Liu P, et al. The role of tocopherol cyclase in salt stress tolerance of rice (Oryza sativa). Sci China Life Sci, 2011, 54: 181-188, doi: $10.1007 / \mathrm{s} 11427-011-4138-1$

Tocopherols and tocotrienols, collectively known as vitamin E, are amphiphilic lipids and are synthesized exclusively by the photosynthetic organisms [1]. Vitamin E is an essential component of the human diet and performs numerous critical functions including quenching and scavenging various reactive oxygen species (ROS) and free radicals and protecting polyunsaturated fatty acids from lipid peroxidation [2,3]. Tocopherols are composed of a polar chromanol head and a lipophilic isoprenoid tail derived from homogentisate and phytyl diphosphate, respectively [4]. In membrane lipid bilayers, the polar chromanol head is exposed to the surface of the membrane and the lipophilic isoprenoid tail associates with lipids. In nature there are four forms of toco-

*Corresponding authors (email: jszhang@genetics.ac.cn; sychen@genetics.ac.cn) pherols, namely $\alpha-, \beta-, \gamma$ - and $\delta$-tocopherol, differing only in the number and position of methyl substituents attached to the chromanol ring. Plant tissues vary enormously in their contents and compositions of tocopherols. While $\alpha$-tocopherol is the predominant form in leaves, $\gamma$-tocopherol is rich in seeds of many plant species $[5,6]$.

Because of its high economic value, substantial efforts have been devoted to elucidating the tocopherol biosynthetic pathway in plants and cyanobacteria in recent years $[7,8]$. Tocopherol cyclase (VTE1) catalyzes the penultimate step of tocopherol synthesis, converting the substrate 2,3-dimethyl-5-phytyl-1,4-benzoquinone (DMPBQ) to $\gamma$-tocopherol [8-10]. Final methylation by $\gamma$-tocopherol methyltransferase $(\gamma$-TMT) results in the production of $\alpha$-tocopherol [11]. TC/VTE1 activity is evolutionarily conserved 
between plants and cyanobacteria [8], and is a major limiting factor of tocopherol synthesis in leaves of Arabidopsis thaliana as well [12].

Under natural conditions, plants are constantly challenged by a variety of biotic and abiotic stresses. High salinity is one of the major abiotic stresses that severely reduce plant growth and crop production. An important response to the high salinity stress is the accelerated generation and/or accumulation of ROS including hydrogen peroxide, hydroxyl radicals, and superoxide anions, which could damage the cellular components or even cause cell death [13-17]. To deal with oxidative stress, plants utilize enzymatic and non-enzymatic antioxidants, of which the latter includes vitamin $\mathrm{E}$, to protect their cells from oxidative damage by scavenging ROS $[18,19]$.

Previous studies have shown that oxidative stress activated the expression of genes responsible for the synthesis of tocopherols in higher plants and water deficiency resulted in an increase of tocopherol concentration in plant tissues [20-22]. In addition, the concentration of $\alpha$-tocopherol precursor and abiotic stress tolerance are correlated [23]. In transgenic lettuce plants overexpressing Arabidopsis TC/VTE1, the chlorophyll content increased by up to $35 \%$ [24] and transgenic tobacco plants overexpressing Arabidopsis TC/VTE1 showed enhanced tolerance to drought stress [25].

However, to our knowledge, roles for tocopherols in the response to high salt stress in rice have not been clearly demonstrated. In the present study, we conducted research on the responses of OSVTE1 knockdown and overexpression of transgenic lines to high salinity to assess functions of tocopherols in rice. The results showed that overexpression of OsVTE1 could increase the tolerance to salt stress by efficiently scavenging ROS in rice.

\section{Materials and methods}

\subsection{Growth conditions}

Seeds of rice (Oryza sativa subsp. japonica cv. TP309), and transgenic plants were sown in pots $(8 \mathrm{~cm} \times 10 \mathrm{~cm})$ containing vermiculite soaked with water. All plants were grown under white fluorescent light $\left(600 \mu \mathrm{mol} \mathrm{m} \mathrm{m}^{-1}, 12 \mathrm{~h}\right.$ photoperiod) and $75 \%$ relative humidity at $28^{\circ} \mathrm{C}$ in a greenhouse.

\subsection{RNA isolation and RT-PCR and real-time quanti- tative RT-PCR analysis}

Total RNA isolation was performed following the method described by Zhang et al. [26]. First-strand cDNA synthesis was primed with Oligo(dT) $)_{15}$ and catalyzed with M-MLV reverse transcriptase (Promega) at $37^{\circ} \mathrm{C}$ for $1.5 \mathrm{~h}$. A fivefold dilution of the reaction products was used as templates for RT-PCR and real-time quantitative RT-PCR analysis. The gene-specific primers RT-OsVTE1 (5'-AGGGCCTATTCATCTCTACC-3') and RT-OsVTE2 (5'-GGTGTCCATTCCCGAGTGCAGGCA-3') were used for RT-PCR. Real-time quantitative RT-PCR analysis used the SYBR Green PCR Master Mix, an ABI 7000 sequence detection system (Applied Biosystems), and the gene-specific primers Rtime1 (5'-TGCAATGTCTTCTCAGGCGC-3') and Rtime2 (5'-GCTTCTATTTCAACCAGATG-3'). Quantitative RTPCR results were analyzed with Microsoft Excel software.

\subsection{Vector construction and rice transformation}

The full-length cDNA sequence of OsVTE1 (Os02g0276500) was amplified by RT-PCR using gene-specific primer pairs (5'-CGGGGTACCAGGGCCTATTCATCTCTACC-3' and 5'-CGCGGATCCAGCATCAGCATGGACCTCGC-3'), and cloned into the Kpn I and BamH I sites of the binary vector pBIN438 as described previously [27]. The gene was driven by two copies of the $35 \mathrm{~S}$ promoter. The tobacco mosaic virus $\Omega$ sequence was also included downstream of the $35 \mathrm{~S}$ promoter to enhance the translation efficiency. The construct was introduced into Agrobacterium tumefaciens strain AGL1 and then transformed into rice (O. sativa subsp. japonica cv. TP309) as described by Hiei et al. [28]. For the construction of the RNAi vector pZHOsVTE1, a 489-bp fragment of the OsVTE1 gene (from 409 to $897 \mathrm{bp}$ ) was amplified using the specific primers RNAiF containing the $X b a$ I and $S a c$ I sites (5'-TGCTCTAGAGAGCTCCAGTTCACCGAGAAATCC-3') and RNAiR containing the Sal I and $\mathrm{Sac}$ I sites (5'-ACCGTCGACGAGCTCAGATGCGCCTGAGAAGAC-3'). The sense and antisense fragments were assembled into vector pZH01. The RNAi construct pZHOSVTE1 contains the $35 \mathrm{~S}$ promoter, the NOS terminator, and a fragment of the GUS gene between the two inserted 489-bp fragments of the OsVTE1 gene.

\section{$1.4 \quad \mathrm{H}_{2} \mathrm{O}_{2}$ localization in situ}

Plant leaves were excised and immersed in a $1 \%$ solution of 3',3'-diamino benzidine (DAB) in Tris- $\mathrm{HCl}$ buffer ( $\mathrm{pH} 6.5)$. After vacuum-infiltration for $30 \mathrm{~min}$, the samples were incubated at room temperature for $20 \mathrm{~h}$ in the dark. When the brown spots were seen clearly, leaves were bleached by immersion in boiling ethanol to visualize the brown spots. The brown spots were characteristic of the reaction of DAB with $\mathrm{H}_{2} \mathrm{O}_{2}$.

\subsection{Determination of the total chlorophyll content}

About $0.1 \mathrm{~g}$ leaf tissue excised into segments $2-3 \mathrm{~cm}$ in length was immersed in the extract solution (45\% ethanol: $45 \%$ acetone: $10 \%$ water, $\mathrm{V} / \mathrm{V}$ ) at room temperature until the leaves were bleached. The absorbance of the extracts was measured at $647 \mathrm{~nm}$ and $665 \mathrm{~nm}$. The total chlorophyll 
content was calculated [29] and expressed as $\mathrm{mg} \mathrm{g}^{-1} \mathrm{FW}$. Three replicate experiments were performed.

\subsection{Promoter GUS analysis}

The OsVTE1 gene promoter (DNA fragment from 1 to 1300 bp upstream of the translation start site) was amplified using the primers 5'-CCAAGCTTGCACGACCATAGGCGTGGGT-3' and 5'-GCTCTAGAGCTGATGCTGCGGGCGGGCA-3', confirmed by sequencing and cloned into the Hind III and BamH I sites of vector pBI121. The plasmid was introduced into the receptor rice $(O$. sativa subsp. japonica cv. TP309) by A. tumefaciens-mediated transformation as described by Hiei et al. [28]. The GUS assays at different developmental stages were performed according to the method described by Jefferson et al. [30].

\subsection{Salt treatments}

All three-week-old seedlings including the control and transgenic plants grown under normal conditions were transferred into $100 \mathrm{mmol} \mathrm{L}^{-1} \mathrm{NaCl}$ solution for $10 \mathrm{~d}$, rinsed three times with water and then subjected to regular irrigation for recovery. Three replicate experiments were performed.

\section{Results}

\subsection{Expression of OsVTE1}

The full-length OsVTE1 (Os02g0276500) cDNA was amplified using gene-specific primers by RT-PCR. OsVTE1 had an open reading frame (ORF) of $1413 \mathrm{bp}$ and encoded a peptide of 471 amino acids. Sequence alignment analysis indicated that OsVTE1 exhibited $83.9 \%$ similarity with SXD1 in Zea mays (GenBank accession number AAK60502) and $61.9 \%$ with VTE1 in Arabidopsis thaliana (accession number NP_567906) (Figure 1).

The expression pattern of OSVTE1 under various treatments was investigated by RT-PCR. It could be seen in Figure 2A that OsVTE1 was induced significantly by abiotic stresses including $200 \mathrm{mmol} \mathrm{L} \mathrm{L}^{-1} \mathrm{NaCl}$, drought, $-4^{\circ} \mathrm{C}, 100$ $\mu \mathrm{mol} \mathrm{L}{ }^{-1} \mathrm{H}_{2} \mathrm{O}_{2}, 100 \mu \mathrm{mol} \mathrm{L}{ }^{-1}$ salicylic acid (SA), and 100 $\mu \mathrm{mol} \mathrm{L} \mathrm{L}^{-1}$ abscisic acid (ABA). However, OsVTE1 expression in response to $100 \mu \mathrm{mol} \mathrm{L}{ }^{-1}$ ACC and $\mathrm{H}_{2} \mathrm{O}$ treatment was unchanged. The results suggest that OsVTE1 may be involved in the tolerance of rice to changes in the environment.

Total RNA was extracted from the root, stem, leaf, and spikelet of rice TP309 to study the tissue-specific expression pattern of OsVTE1. As shown in Figure 2B, OsVTE1 was mainly expressed in the leaf, and also could be detected in the root, stem and panicle. To further examine the expression of OSVTE1, the $1.3 \mathrm{~kb}$ promoter region of OSVTE1 was cloned and fused to the expression vector pBI121 containing $\beta$-glucuronidase (GUS) reporter gene (Figure $3 \mathrm{C}$ ). The resulting construct was transferred into rice TP309. Fifteen independent $T_{2}$ transgenic lines were used for the GUS staining assay. Consistent with the results obtained from the RT-PCR assay mentioned above, GUS driven by the OsVTE1 promoter was expressed in the stem, especially in the node, spikelet, particularly in the stamen, and leaf as indicated in Figure 2C (a-h).

\subsection{Phenotype analysis of transgenic plants under salt} stress

An overexpression vector with the full-length cDNA of

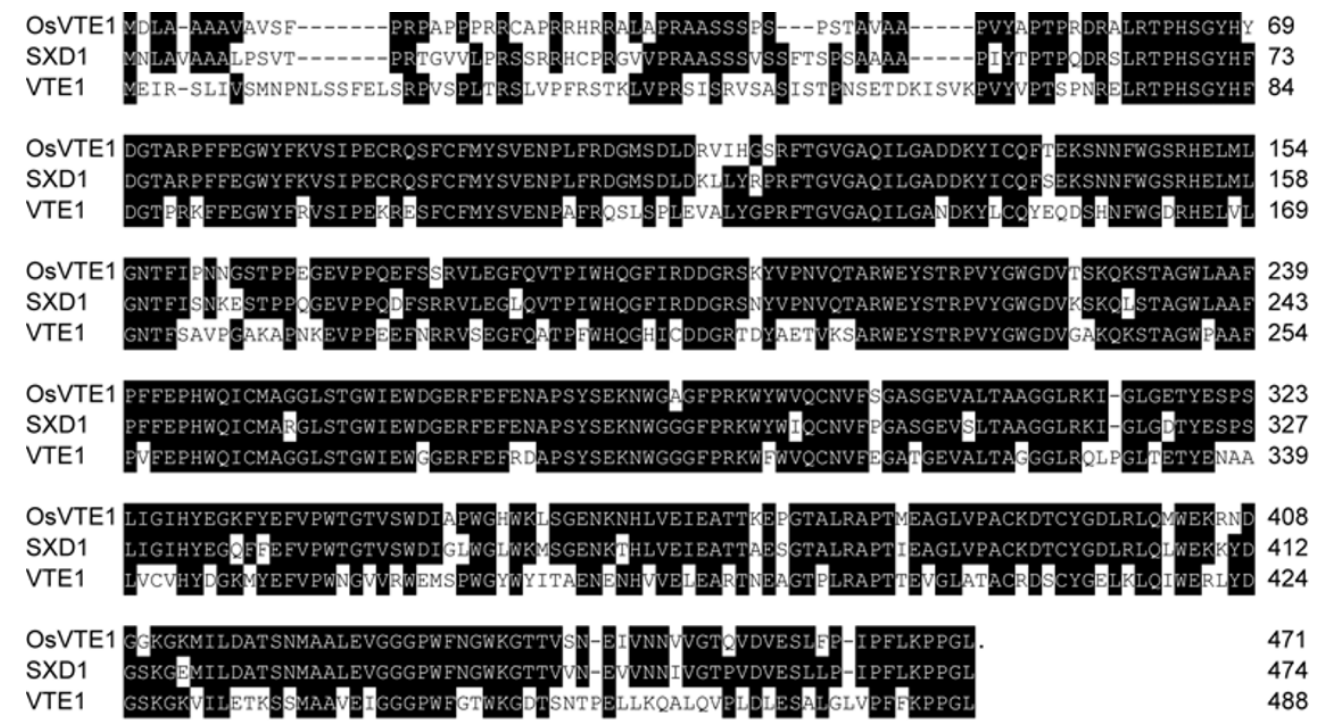

Figure 1 Alignment of the deduced amino acid sequences of OsVTE1, SXD1 in Zea mays (accession number AAK60502) and VTE1 in Arabidopsis thaliana. Alignments were performed using DNA STAR. Consensus amino acid residues are shaded in black. Gaps introduced to maximize the alignments are denoted by hyphens. 

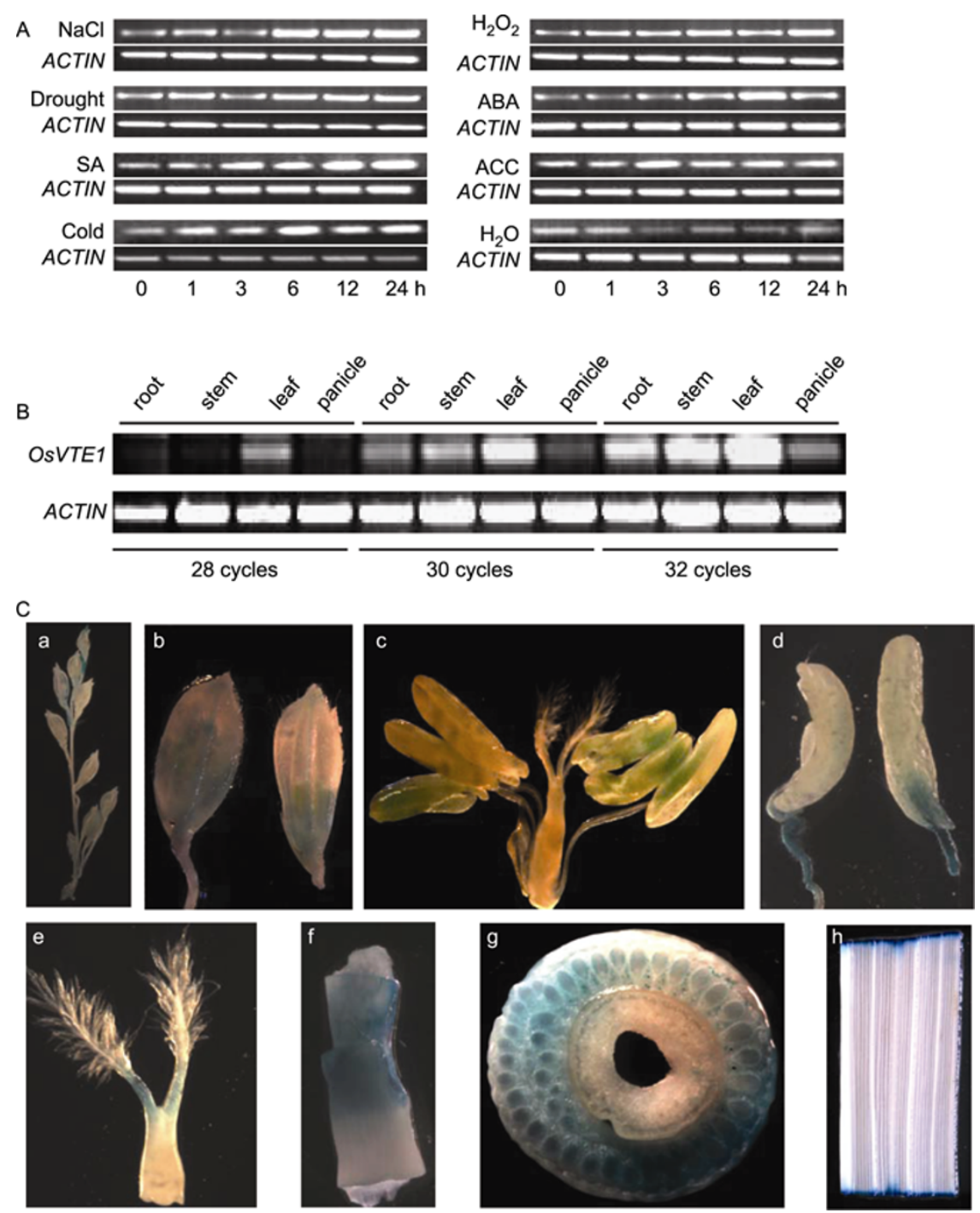

Figure 2 Expression of $O s V T E 1$ in rice. A, Expression of $O s V T E 1$ in rice seedlings in response to salt, $\mathrm{H}_{2} \mathrm{O}_{2}$, drought, ABA, SA, ACC and cold treatments. B, Expression of OSVTE1 in the root, stem, leaf, and spikelet determined by 28, 30, and 32 cycles of RT-PCR with gene-specific primers. C, $O s-$ VTE1 promoter-GUS expression in rice plants: spikelet (a), seed (b), rachilla (c), stamen (d), pistil (e), stem (f, g), and leaf (h).

OsVTE1 under the control of two CaMV35S promoters (OsVTE1-OX) and a RNA interference vector carrying part of the OsVTE1 gene (OsVTE1-RNAi) (Figure 3A and B) were constructed and transformed into the TP309 plants. The expression of OsVTE1 was checked for the OsVTE1-OX and OsVTE1-RNAi transgenic plants by real-time PCR (Figure 3D and E). OsVTE1 gene expression in six of the 11 OsVTE1-OX transgenic lines was higher than that of wild-type TP309. By contrast, OsVTE1 gene expression in most of the OsVTE1-RNAi transgenic plants was lower than that of wild-type TP309. The progeny of six independent lines OsVTE1-OX-14-2, 20-3, 75 and OsVTE1-RNAi-3-2, 13-3, 64 were used for further analysis. No visible phenotypic differences were observed between transgenic plants and control plants when grown under normal conditions (Figure 4A).

Given that the expression of OSVTE1 was induced by
$\mathrm{NaCl}$ treatment, the phenotypes of the OsVTE1 transgenic plants were compared with those of control plants under the salt treatment. After growth under normal conditions for 3 weeks, all of the transgenic and control plants were transferred to $100 \mathrm{mmol} \mathrm{L}^{-1} \mathrm{NaCl}$ solution for salt treatment and the phenotypes were observed after $10 \mathrm{~d}$. Nearly $80 \%$ of the leaves of the 3 OsVTE1-RNAi lines were wilted. The control plants were short, yet the leaves were still green. The growth of OsVTE1-OX plants was much better than that of the controls (Figure 4B).

After treatment for $10 \mathrm{~d}$, all plants were rinsed 3 times with water, then subjected to regular irrigation for recovery. As shown in Figure $4 \mathrm{C}$ and E, the OsVTE1-OX plants recovered more quickly than the others and about $60 \%-80 \%$ of them could survive after resuming irrigation for $10 \mathrm{~d}$. In contrast, the survival rate of the control plants TP309 was about $40 \%$. The lowest survival rate was seen in the OsVTE1-RNAi 
A

pBin438-OSVTE1
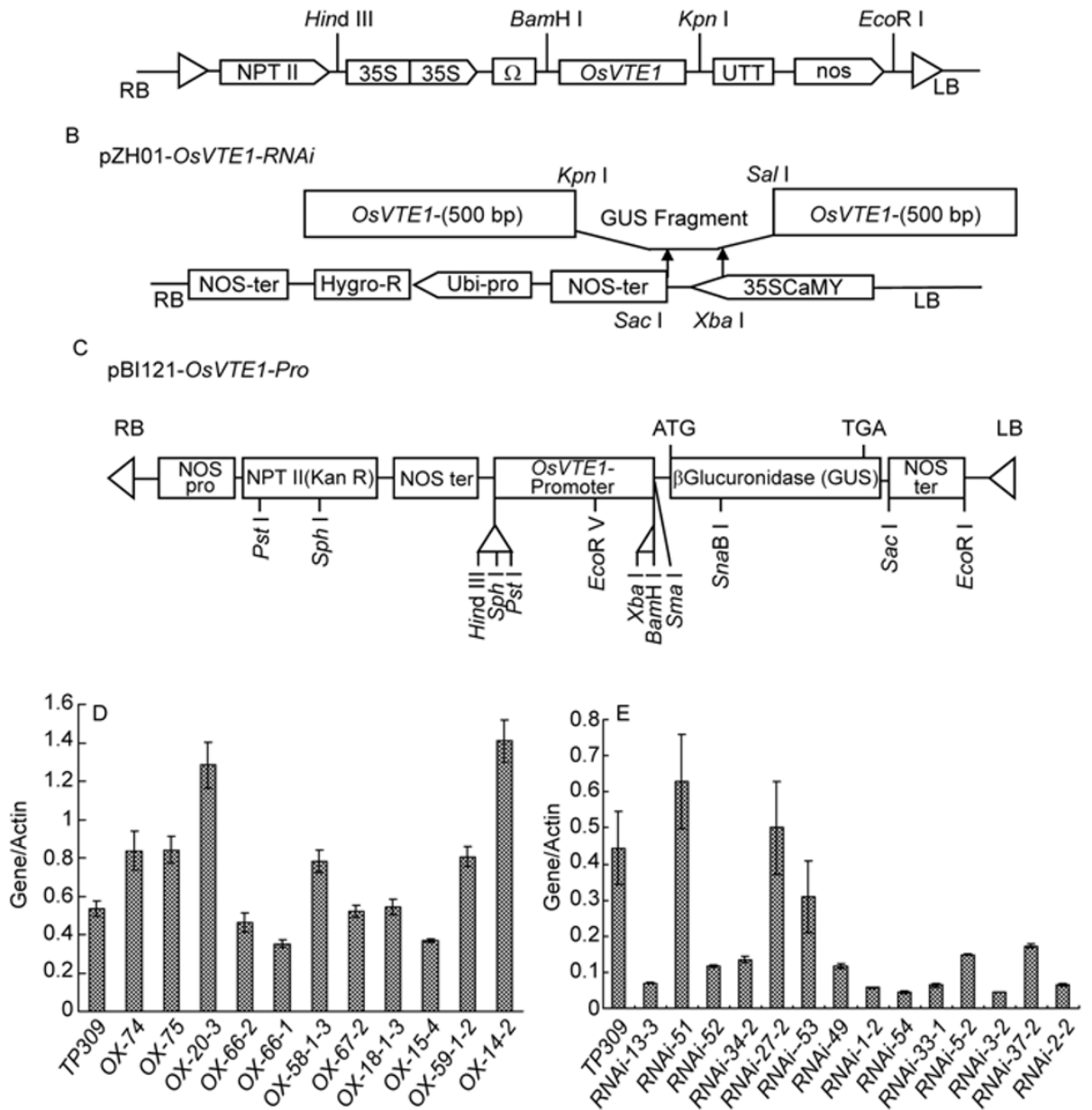

Figure 3 Transgenic plant materials. A, Schematic diagram of overexpression vector pBin438-OsVTE1. B, Schematic diagram of RNA interference vector pZH01-OsVTE1-RNAi. C, Schematic diagram of promoter GUS vector pBI121-OsVTE1-promoter. D, Expression of OsVTE1 in overexpression plants determined by real-time PCR. E, Expression of OsVTE1 in RNA interference plants determined by real-time PCR.

plants; most of the plants died and only about $30 \%$ of them survived.

Leaf chlorophyll content provides valuable information about the physiological status of plants and may be used as an indicator of photosynthetic activity [31]. Changes in chlorophyll content can occur as a result of exposure to environmental stresses during growth. Figure 4D shows that the chlorophyll content in all plants decreased after salt stress, though in different degrees. For the OsVTE1-RNAi plants, the chlorophyll content was reduced by about $50 \%-60 \%$, compared with about $40 \%$ in the control plants and about $26 \%$ in the OsVTE1-OX plants.

\subsection{Overexpression of $O S V T E 1$ increased the antioxi- dant capacity of rice seedlings}

Salt stress can induce the accumulation of ROS such as $\mathrm{H}_{2} \mathrm{O}_{2}$ [32]. After treatment with $100 \mathrm{mmol} \mathrm{L}^{-1} \mathrm{NaCl}$ for 10 $\mathrm{d}$, the leaves of three-week-old rice seedlings were excised. Accumulation of $\mathrm{H}_{2} \mathrm{O}_{2}$ was evaluated in situ by histochemi- cal detection with 3,3'-diaminobenzidine (DAB) staining. As shown in Figure 5, salt stress produced very little $\mathrm{H}_{2} \mathrm{O}_{2}$ brown spots in the OsVTE1-OX plants. Half of the leaves of the TP309 plants became brown under salt stress. More serious damage was observed in the OsVTE1-RNAi plants, in which almost the whole leaf became brown. These results indicated that overexpression of OsVTE1 might be able to efficiently eliminate $\mathrm{H}_{2} \mathrm{O}_{2}$ produced by salt stress.

\section{Discussion}

Among the characterized functions of tocopherols in cells, scavenging and quenching ROS and lipid-soluble byproducts of oxidative stress was the most predominant [2,33,34]. Salt stress could induce the accumulation of ROS such as hydrogen peroxide, superoxide and hydroxyl radicals [32]. At the same time, the amounts of various antioxidants including tocopherols increased strongly to scavenge ROS. Based on the studies of 10 different grass species, it was 

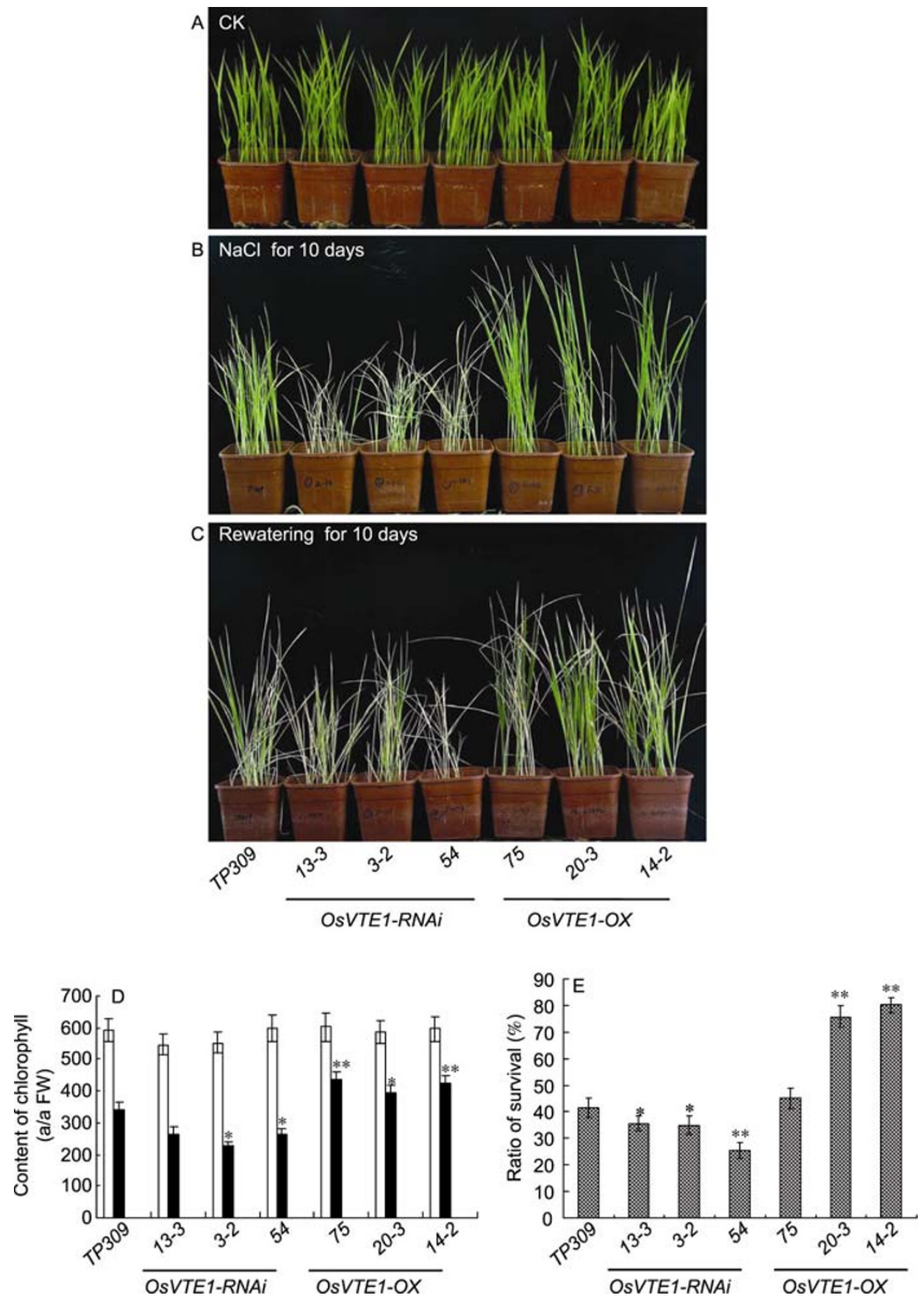

Figure 4 Salt stress tolerance of the OsVTE1-RNAi and OsVTE1-OX transgenic plants. The stress treatments were conducted using plants growing under normal conditions for 3 weeks. A, Normal conditions for 3 weeks. B, $100 \mathrm{mmol} \mathrm{L}{ }^{-1} \mathrm{NaCl}$ stress for $10 \mathrm{~d}$. C, 10-day-recovery after $100 \mathrm{mmol} \mathrm{L}^{-1} \mathrm{NaCl}$ stress for $10 \mathrm{~d}$. D, The chlorophyll content after $100 \mathrm{mmol} \mathrm{L}^{-1} \mathrm{NaCl}$ treatment for $10 \mathrm{~d}$. White represents $\mathrm{CK}$, black represents NaCl treatment. Each column represents an average of three replicates, and bars indicate the SD. E, The ratio of survival after $10 \mathrm{~d}$ of recovery. Each column represents an average of three replicates, and bars indicate the SD. * and ** indicate significant differences from the corresponding control plants in the same treatments at $P<0.05$ and $P<0.01$, respectively.

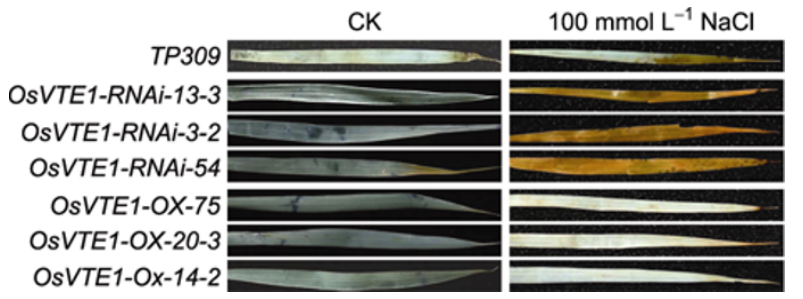

Figure 5 DAB (3,3-diaminobenzidine) staining after $100 \mathrm{mmol} \mathrm{L}^{-1} \mathrm{NaCl}$ stress for $10 \mathrm{~d}$. reported that drought stress led to an increase in tocopherol concentration of one- to three-fold in nine of the 10 species and highly significant correlations were observed between stress tolerance and tocopherol concentration [21,23]. The accumulation of antioxidants under stress was at least partially due to induction of gene expression. In Arabidopsis, HPPD (p-hydroxyphenylpyruvate dioxygenase) and HPT1 (homogentisate phytyltransferase), two genes encoding enzymes involved in tocopherol synthesis, were induced under 
light stress [35]. In contrast, the expression level of AtVTE1 was not altered significantly during stress in Arabidopsis [35]. In Arabidopsis, experiments using leaf discs from two vitamin E mutants, a tocopherol cyclase mutant (vte1) and a homogentisate phytyl transferase mutant (vte2), indicated that tocopherols function as protectors of membrane lipids against peroxidative damage under high light intensity combined with low temperature conditions [36]. Our results demonstrated that different expression levels of OSVTE1 had a strong impact on the loss of chlorophyll content under high salt stress in rice. In this regard, we could conclude that OsVTE1 plays an important role in protecting the photosynthesis system in rice when exposed to salt stress.

Manipulation of tocopherol content has been reported in Arabidopsis by overexpressing the genes encoding the enzymes for tocopherol biosynthesis. Overexpression of HPT/VTE2 and TC/VTE1 increased levels of tocopherols up to 4.4- and 7-fold, respectively, in Arabidopsis leaves [12,37]. To study the impact of tocopherol content on abiotic stress tolerance in rice, we produced both OsVTE1 overexpressed and knocked-down rice transgenic plants. The results indicated that overexpression of OsVTE1 could eliminate $\mathrm{H}_{2} \mathrm{O}_{2}$ efficiently in rice. On the contrary, knock-down of OsVTE1 resulted in a significant increase of $\mathrm{H}_{2} \mathrm{O}_{2}$ amounts under salt stress (Figure 5). The salt stress tolerance testing showed that the plants overexpressing OsVTE1 had higher salt tolerance than control and OsVTE1-RNAi plants (Figure 4). It is suggested that enhancement of the tocopherol level might be related to the function of preventing lipid peroxidation and scavenging ROS.

In plants, tocopherol composition varies between different tissues within a species. Generally, $\alpha$-tocopherol accumulates mainly in leaves, and seeds are rich in $\gamma$-tocopherol. $\beta$ - and $\delta$-tocopherol are not very abundant in most plants species. $\alpha$-tocopherol together with other hydrophilic antioxidants glutathione and ascorbate has been proposed to participate in the scavenging of ROS [38]. By comparing the effects of a general tocopherol deficiency (in HPT:RNAi) versus a replacement of $\alpha$-tocopherol with $\gamma$-tocopherol (in $\gamma$-TMT:RNAi) in oxidative stress scenarios, Abbasi et al. [39] reported that $\alpha$ - and $\gamma$-tocopherol played specific roles in abiotic stress responses of transgenic tobacco. However, from the report by Kruk et al. [40], the inhibitory effect of interrupted tocopherol biosynthesis on singlet oxygen scavenging in PSII of Chlamydomonas reinhardtii could be overcome by adding exogenous membrane-permeable short chain $\alpha$ - and $\gamma$-tocopherol derivatives, indicating that $\alpha$-tocopherol could be substituted by $\gamma$-tocopherol in leaves. Biochemical analysis of an Arabidopsis plant (vte4-1) carrying a functional null mutation in the $\gamma$-TMT gene showed similar results. The mutant accumulated high levels of $\gamma$-tocopherol instead of $\alpha$-tocopherol. $\alpha$-tocopherol can be replaced by $\gamma$-tocopherol in vte4- 1 to protect the photosynthetic apparatus against oxidative stress [41].
In summary, we have reported that OsVTE1, which encodes atocopherol cyclase, was induced by various abiotic stresses. OsVTE1-OX plants accumulated less $\mathrm{H}_{2} \mathrm{O}_{2}$ than did control plants. This result, together with the phenotype analysis under salt stress, suggested that over-expressing OsVTE1 could improve the tolerance to high salt stress in rice. A future goal is to measure tocopherol content of transgenic rice lines overexpressing and RNA-interfering OsVTE1 and further verify the relationships among OsVTE1 expression, tocopherol content and rice performance under salt stress.

This work was supported by the National Basic Research Program of China (Grant No. 2006CB100102) and National High-Tech Project (Grant No. 2006AA10Z18201)

1 Munne-Bosch S, Alegre L. The function of tocopherols and tocotrienols in plants. Crit Rev Plant Sci, 2002, 21: 31-57

2 Bramley P M, Elmadfa I, Kafatos A, et al. Vitamin E. J Sci Food Agric, 2000, 80: 913-938

3 Szymańska R, Kruk J. Occurrence and function of tocochromanols in plants, animals and men. Postepy Biochem, 2007, 53: 174-181

4 Neely W C, Martin J M, Barker S A. Products and relative reaction rates of the oxidation of tocopherols with singlet molecular oxygen. Photochem Photobiol, 1988, 48: 423-428

5 Grusak M A, DellaPenna D. Improving the nutrient composition of plants to enhance human nutrition and health. Annu Rev Plant Physiol Plant Mol Biol, 1999, 50: 133-161

6 Desel C, Hubbermann E M, Schwarz K, et al. Nitration of $\gamma$-tocopherol in plant tissues. Planta, 2007, 226: 1311-1322

7 Cheng Z, Sattler S, Maeda H, et al. Highly divergent methyltransferases catalyze a conserved reaction in tocopherol and plastoquinone synthesis in cyanobacteria and photosynthetic eukaryotes. Plant Cell, 2003, 15: 2343-2356

8 Sattler S E, Cahoon E B, Coughlan S J, et al. Characterization of tocopherol cyclases from higher plants and cyanobacteria: Evolutionary implications for tocopherol synthesis and function. Plant Physiol, 2003, 132: 2184-2195

9 Arango Y, Heise K P. Tocopherol synthesis from homogentisate in Capsicum апnиит L. (yellow pepper) chromoplast membranes: Evidence for tocopherol cyclase. Biochem J, 1998, 336: 531-533

10 Porfirova S, Bergmuller E, Tropf S, et al. Isolation of an Arabidopsis mutant lacking vitamin $\mathrm{E}$ and identification of a cyclase essential for all tocopherol biosynthesis. Proc Natl Acad Sci USA, 2002, 99: 12495-12500

11 Shintani D, DellaPenna D. Elevating the vitamin E content of plants through metabolic engineering. Science, 1998, 282: 2098-2100

12 Kanwischer M, Porfirova S, Bergmuller E, et al. Alterations in tocopherol cyclase activity in transgenic and mutant plants of Arabidopsis affect tocopherol content, tocopherol composition, and oxidative stress. Plant Physiol, 2005, 137: 713-723

13 Bolwell G P, Wojtaszek P. Mechanisms for the generation of reactive oxygen species in plant defence-a broad perspective. Physiol Mol Plant Pathol, 1997, 51: 347-366

14 Lamb C, Dixon R A. The oxidative burst in plant disease resistance. Annu Rev Plant Physiol Plant Mol Biol, 1997, 48: 251-275

15 Noctor G, Foyer C H. Ascorbate and glutathione: keeping active oxygen under control. Annu Rev Plant Physiol Plant Mol Biol, 1998, 49: 249-279

16 Karpinski S, Reynolds H, Karpinska B, et al. Systemic signaling and acclimation in response to excess excitation energy in Arabidopsis. Science, 1999, 284: 654-657

17 Orozco-Cardenas M, Ryan C A. Hydrogen peroxide is generated systemically in plant leaves by wounding and systemin via the octa- 
decanoid pathway. Proc Natl Acad Sci USA, 1999, 96: 6553-6557

18 Dat J, Vandenabeele S, Vranová E, et al. Dual action of the active oxygen species during plant stress responses. Cell Mol Life Sci, 2000, 57: 779-795

19 Alscher R G, Erturk N, Heath L S. Role of superoxide dismutases (SODs) in controlling oxidative stress in plants. J Exp Bot, 2002, 53: 1331-1341

20 Shao H B, Chu L Y. Plant molecular biology in China: Opportunities and Challenges. Plant Mol Biol Rep, 2005, 23: 345-358

21 Shao H B, Chu L Y, Wu G, et al. Changes of some anti-oxidative physiological indices under soil water deficits among 10 wheat (Triticum aestivum L.) genotypes at tillering stage. Colloids Surf B Biointerfaces, 2007, 54: 143-149

22 Wu G, Wei Z K, Shao H B. The mutual responses of higher plants to environment: physiological and microbiological aspects. Colloids Surf B Biointerfaces, 2007, 59: 113-119

23 Pourcel L, Routaboul J M, Cheynier V. Flavonoid oxidation in plants from biochemical properties to physiological functions. Trends Plant Sci, 2007, 12: 29-36

24 Lee K, Lee S M, Park S R, et al. Overexpression of Arabidopsis homogentisate phytyltransferase or tocopherol cyclase elevates vitamin E content by increasing gamma-tocopherol level in lettuce (Lactuca sativa L.). Mol Cells, 2007, 24: 301-306

25 Liu X, Hua X, Guo J, et al. Enhanced tolerance to drought stress in transgenic tobacco plants overexpressing VTE1 for increased tocopherol production from Arabidopsis thaliana. Biotechnol Lett, 2008, 30: $1275-1280$

26 Zhang J S, Gu J, Liu F H, et al. A gene encoding a truncated large subunit of rubisco is transcribed and salt-inducible in rice. Theor Appl Genet, 1995, 91: 361-366

27 Xie C, Zhang Z G, Zhang J S, et al. Spatial expression and characterization of a putative ethylene receptor protein NTHK1 in tobacco. Plant Cell Physiol, 2002, 43: 810-815

28 Hiei Y, Ohta S, Komari T, et al. Efficient transformation of rice (Oryza sativa L.) mediated by Agrobacterium and sequence analysis of the boundaries of the T-DNA. Plant J, 1994, 6: 271-282

29 Inskeep W P, Bloom P R. Extinction coefficients of chlorophyll a and b in N,N-dimethylformamide and 80\% acetone. Plant Physiol, 1985, 77: 483-485

30 Jefferson R A, Kavanagh T A, Bevan M W. GUS fusions: Beta-glucuronidase as a sensitive and versatile gene fusion marker in higher plants. EMBO J, 1987, 6: 3901-3907

31 Schreiber U, Hormann H, Neubauer C, et al. Assessment of photosystem II photochemical quantum yield by chlorophyll fluorescence quenching analysis. Aust J Plant Physiol, 1995, 22: 209-220

32 Hasegawa P M, Bressan R A, Zhu J K, et al. Plant cellular and molecular responses to high salinity. Annu Rev Plant Physiol Plant Mol Biol, 2000, 51: 463-499

33 Brigelius-Flohe R, Traber M G. Vitamin E: function and metabolism. FASEB J, 1999, 13: 1145-1155

34 Ricciarelli R, Zingg J M, Azzi A. Vitamin E: protective role of a Janus molecule. FASEB J, 2001, 15: 2314-2325

35 Collakova E, DellaPenna D. The role of homogentisate phytyltransferase and other tocopherol pathway enzymes in the regulation of tocopherol synthesis during abiotic stress. Plant Physiol, 2003, 133: 930-940

36 Havaux M, Eymery F, Porfirova S, et al. Vitamin E protects against photoinhibition and photooxidative stress in Arabidopsis thaliana. Plant Cell, 2005, 17: 3451-3469

37 Collakova E, DellaPenna D. Isolation and functional analysis of homogentisate phytyltransferase from Synechocystis sp. PCC 6803 and Arabidopsis. Plant Physiol, 2001, 127: 1113-1124

38 Foyer C H, Noctor G. Redox sensing and signalling associated with reactive oxygen in chloroplasts, peroxisomes and mitochondria. Physiol Plant, 2003, 119: 355-364

39 Abbasi A R, Hajirezaei M, Hofius D, et al. Specific roles of alphaand gamma-tocopherol in abiotic stress responses of transgenic tobacco. Plant Physiol, 2007, 143: 1720-1738

40 Kruk J, Holländer-Czytko H, Oettmeier W, et al. Tocopherol as singlet oxygen scavenger in photosystem II. J Plant Physiol, 2005, 162: 749-757

41 Bergmüller E, Porfirova S, Dörmann P. Characterization of an Arabidopsis mutant deficient in gamma-tocopherol methyltransferase. Plant Mol Biol, 2003, 52: 1181-1190

Open Access This article is distributed under the terms of the Creative Commons Attribution License which permits any use, distribution, and reproduction in any medium, provided the original author(s) and source are credited. 